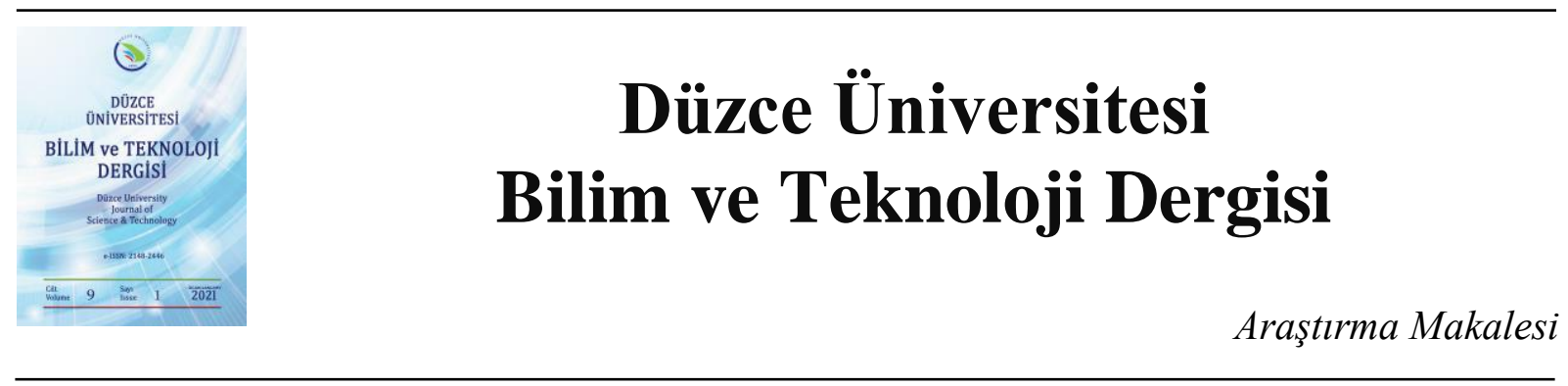

\title{
Fotovoltaik Sistemler için Üç Fazlı Evirici Tasarımı ve Kontrolü
}

\author{
(D) Naki GÜLER ${ }^{\mathrm{a},{ }^{*}, \text { (D) Samet BİRİCİ }}{ }^{\mathrm{b}}$ \\ ${ }^{a}$ Elektrik ve Enerji Bölümü, Teknik Bilimler Meslek Yüksekokulu, Gazi Üniversitesi, Ankara, TÜRKIYE \\ ${ }^{b}$ Elektrik Elektronik Mühendisliği Bölümü, Mühendislik Fakültesi, Lefke Avrupa Üniversitesi, Lefke, KIBRIS \\ * Sorumlu yazarn e-posta adresi: gulern@ gazi.edu.tr
}

DOI : 10.29130/dubited.692055

\begin{abstract}
ÖZET
$\mathrm{Bu}$ çalışmada, fotovoltaik (PV) sistemler için hem şebeke bağlantılı hem de ada durumda güç akışını sağlayabilen bir eviricinin tasarımı ve kontrolü sunulmuştur. Şebekede kesinti olması durumunda, önerilen güç ve kontrol yapısı güneş panellerinden dâhili yüklere güç akışı sağlamaktadır. Böylece, ışınlama süresi boyunca, kesintilerin yükler üzerindeki etkisi azaltılmış ve PV'de üretilen güç maksimum seviyede kullanılmıştır. Ayrıca, PV panellerden maksimum seviyede güç transferi için Maksimum Güç Noktası Takip (MPPT) algoritması kullanılmıştır. MPPT algoritması evirici için bir referans akım üretecek biçimde uyarlanmıştır. Şebeke kesintisi durumunda sistem gerilim kontrollü olarak çalışmaktadır ve referans akım yük gerilimi ile nominal gerilim arasındaki hataya bağlı olarak bir çıkış üreten PI kontrolör tarafindan belirlenmektedir. Önerilen sistem, MATLAB/Simulink ortamında modellenmiş ve doğrulanmıştır. Sonuçlar, önerilen sistemin her iki çalışma durumunda da güç akışını başarıyla sağladığını göstermektedir.
\end{abstract}

Anahtar Kelimeler: Evirici, Model Öngörülü Kontrol, Maksimum Güç Noktası Takibi

\section{Design and Control of Three-Phase Inverter for Photovoltaic Systems}

\begin{abstract}
In this study, design and control of an inverter that provides the power flow both in grid-connected and in island operation conditions for photovoltaic (PV) systems are presented. In the grid interruption events, the proposed power and control structure provides the power flow from solar panels to internal loads. Thus, during the irradiation period, the interruption effect on the load is minimized and the generated PV power is used at the maximum level. Furthermore, Maximum Power Point Tracking (MPPT) algorithm is used for maximum power transfer from PV panels to grid. The MPPT algorithm modified to generate a reference current for the inverter. The reference current is applied to Model Predictive Control (MPC) technique which is a sensitive and fast control method. In case of grid interruption, the system works based on voltage controlled and the reference current is determined by PI controller which generates an output by depending on the voltage error between load and nominal voltages. The proposed system is modelled and verified in MATLAB/Simulink environment. The results show that the proposed system successfully provides the power flow in both operation modes.
\end{abstract}

Keywords: Inverter, Model Predictive Control, Maximum Power Point Tracking

Geliş: 20/02/2020, Düzeltme: 18/11/2020, Kabul: 24/11/2020 


\section{GİRIS}

Elektrik üretimi için kullanılan doğal kaynaklardaki azalma ve artan enerji talebi, güneş enerjisinden elektrik üretiminin yaygınlaşmasındaki en büyük faktör olarak söylenebilir. Bununla birlikte teknolojik gelişmeler de kullanılabilirlik açısından önemli rol oynamıştır. Güneş panellerinin doğru gerilim üretmesi, şebeke entegrasyonu ve birçok alıcıda doğrudan kullanımını engellemektedir. $\mathrm{Bu}$ nedenle hem yüksek güçlü güneş santrallerinde hem de düşük güçlü sistemlerde eviriciler kullanılmaktadır[1], [2]. Evirici girişine uygulanan doğru gerilim seviyesinin artırılması için PV sistemlerde DA/DA çevirici kullanımı da yaygın modeller arasında yer almaktadır [3], [4]. İki aşamalı güç dönüştürücüsü içeren bu yapılarda sistem maliyeti artmakta ve her iki taraf için kontrolör ihtiyacı doğmaktadır. DA/DA çeviricinin sistemden kaldırılması için seri bağl PV panel sayısı artırılarak gerilim seviyesi yükseltilmektedir. Böylece, sadece evirici kullanılmakta ve sistem maliyeti azaltılmaktadır[2], [5].

Güç katmanının yanı sıra, kontrol yöntemleri de PV sistemlerin verimli kullanılması açısından oldukça önemlidir. Güneş panellerinde üretilen gücün maksimum seviyede kullanılması amaciyla MPPT algoritmaları yaygın olarak kullanılmaktadır[6]-[8]. Bu algoritmalar panel ya da panel grubunun maksimum güç ürettiği noktayı aramak prensibine dayalı olarak çalışmakta ve güç dönüştürücüleri için kontrol işareti üretmektedir. MPPT algoritmalarının kontrol kabiliyetlerinin iyileştirilmesi amacıyla ikincil bir kontrol algoritmasıyla birlikte kullanımı da oldukça yaygın bir yöntemdir[2], [6], [9]. Özellikle değişken ışınım koşullarında ikincil algoritmaların etkinliği sistem kararlılı̆̆ı açısından büyük öneme sahiptir. Bulanık mantık tabanlı gerçekleştirilen maksimum güç takibi işleminin klasik metoda göre daha iyi sonuçlar verdiği [6]'da vurgulanmıştır. Benzer olarak, MPC tekniği ile tümleşik olarak uygulanan [9]'daki çalışmada, hızlı ve hassas bir kontrol sağlandığı belirtilmiştir.

Ada durumda çalışan sistemlerde ise yüklere uygulanan gerilimin genlik ve frekans kontrolü oldukça önemlidir[10]. Özellikle yük değişimi gibi geçiş durumlarında olumsuz etkilerin en aza indirgenmesi için kontrolörün hızlı tepki vermesi gerekmektedir. Son yıllarda güç dönüştürücülerinin kontrolünü içeren uygulamalarda yaygın olarak kullanılan kayma kipli kontrol ve model öngörülü kontrol teknikleri oldukça hızlı ve hassas bir kontrol sergilemektedir[11]-[14]. Kayma kipli kontrolde, kontrolör tasarımı sistem performansı açısından önemli olmakla birlikte, tasarımcının deneyimine de bağl1lık göstermektedir. Model öngörülü kontrol yöntemi sistemin matematiksel modelini kullanarak tahmin tabanlı kontrol işlemlerini gerçekleştirmektedir. Kayma kipli kontrol yönteminin sistem parametrelerinden bağımsız çalışması avantaj olarak ön plana çıkarken, MPC tekniğinde değişen sistem parametrelerinin kolaylıkla ifade edilebilmesi bir avantaj olarak görülmektedir. Her iki teknik de dinamik cevap performansı açısından oldukça benzerlik göstermektedir.

Özetlenen çalışmalar doğrultusunda, önerilen sistem tek aşamalı güç dönüştürücüsü, MPPT algoritması ve MPC tekniği kullanılarak tasarlanmıştır. Tek aşamalı güç dönüştürücüsü kullanımı sistem maliyetini azaltacağından sistemin uygulanabilirliğini artırmıştır. Şebeke etkileşimli durumda, PV panellerden maksimum güç transferi ise sistemin etkin bir şekilde kullanımını sağlamaktadır. Eviricinin akım kontrolü için kullanılan MPC tekniği ile kontrollerin hassas ve hızlı bir şekilde gerçekleştirilmesi hedeflenmiştir.

\section{SISTEM MODELI VE KONTROL YAPISI}

Sistem modelinde yer alan güç ve kontrol yapıları Şekil 1'deki blok şemada verilmiştir. Şekilden görüldüğü üzere, yük grubu hem şebeke hem de güneş panelleri üzerinden beslenebilir durumdadır. Güneş panellerinde üretilen doğru gerilim, evirici aracilığıyla alternatif gerilime dönüştürülmektedir. Sistem, şebeke bağlantılı ve ada durum olmak üzere iki çalışma yapısına sahiptir. Şebeke bağlantı noktasında gerilim olması durumunda, Şebeke Algılama algoritması kesiciyi kapalı konuma getirilerek şebeke entegrasyonunu sağlanmaktadır. Aynı zamanda, kontrol işlemleri için gerekli yönlendirmeler de bu algoritma tarafından sağlanmaktadır. Algoritma, şebeke gerilimi standartlarda belirtilen nominal 
değerin \%10 limiti [15], [16] içerisinde iken bağlantıyı sağlamakta, aksi durumda ise kesiciyi açık konuma getirerek sistemin ada duruma geçmesini sağlamaktadır.

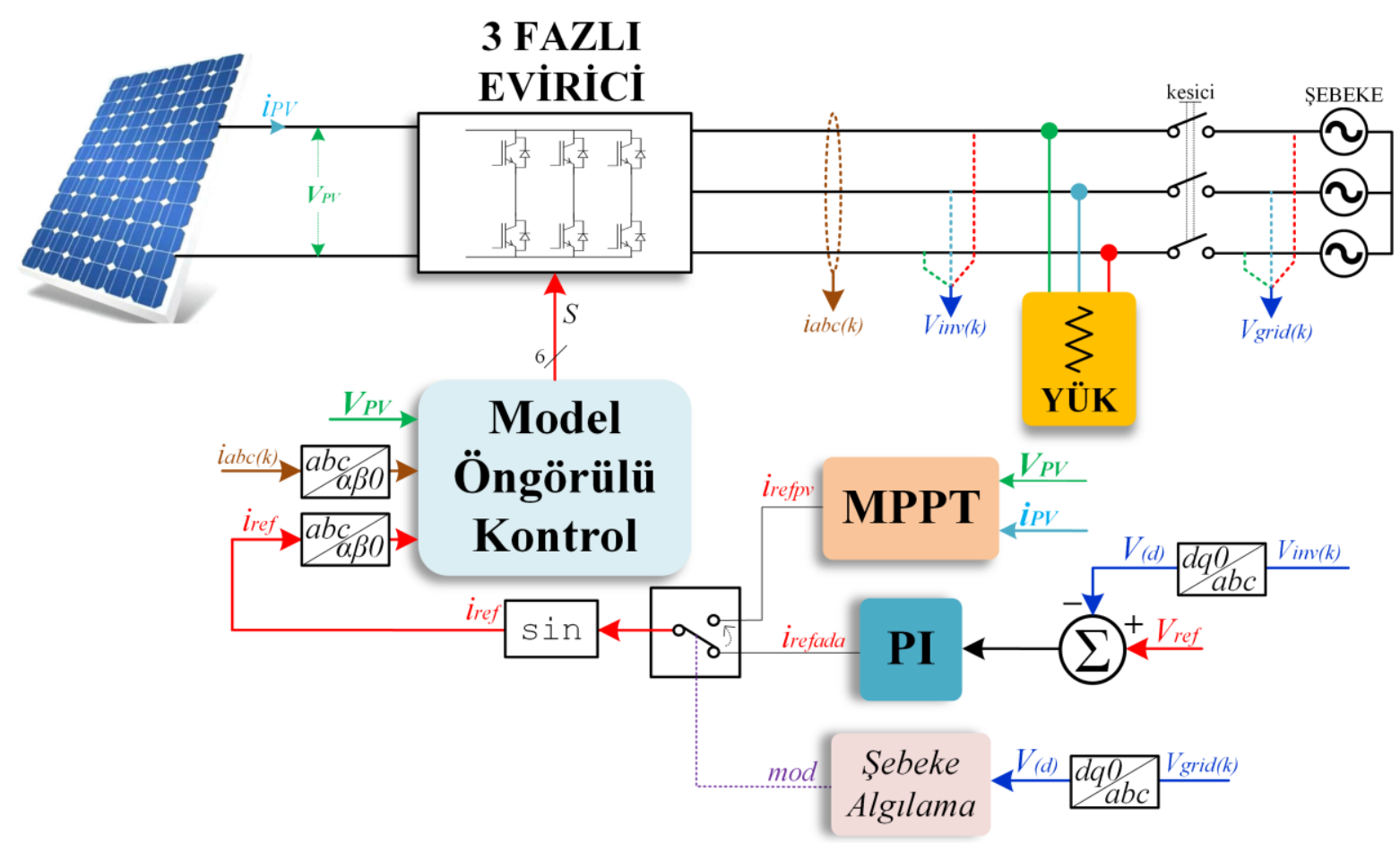

Şekil 1. Sistem modeli

Şebeke bağlı durumda, yüke hem şebekeden hem de güneş panellerinden güç akışı sağlanabilmektedir. Güneş panellerinde üretilen gücün verimli bir şekilde kullanılması için Maksimum Güç Takip Algoritması (MPPT) kullanılmıştır. MPPT algoritması maksimum güç noktasına göre bir referans akım değeri $\left(i_{\text {refpv }}\right)$ üretecek biçimde tasarlanmıştır. Şebeke etkileşimli durumda mod değişkeni bu referans değerin MPC algoritmasına yönlendirilmesini sağlamaktadır. MPC algoritması ise, bu referans değere göre evirici kontrolünü gerçekleştirerek güç akışını yönetmektedir. Evirici çıkışına aktarılan gücün yükte tüketilenden fazla olması durumunda, sistemden şebekeye doğru bir güç akış1 söz konusu olmaktadır. Aksi durumda ise yüke aktarılacak toplam güç, şebeke ve güneş panelinden sağlanmaktadır. Şebekede üretim olmadığı durumda ise yük, güneş panellerinden beslenmektedir. Bu durumda Şebeke Algılama algoritması sayesinde MPC algoritmasında kullanılan referans akım değeri $\left(i_{r e f}\right)$ PI kontrolör çıkışından alınmaktadır. Blok şemadan görüldügü üzere, PI kontrolör referans gerilim değeri ile evirici çıkış gerilimi arasındaki hataya göre bir çıkış sinyali üretmektedir. MPPT algoritmasının devre dışı kaldığı bu durumda, gerilim kontrol algoritması aktif durumdadır. Böylece ada durumda yüklere sabit bir gerilim uygulanırken, şebeke bağlantılı durumda MPPT algoritması tarafindan belirlenen akım referansına göre güç akışı sağlanmaktadır.

\section{A. DEĞİșTír VE GÖZLE MPPT ALGORITMASI}

Yenilenebilir enerji sistemlerinde üretilen gücün verimli bir şekilde kullanılması için güç dönüştürücülerinin kontrolü maksimum güç takip algoritmalarıyla sağlanmaktadır. Değiştir ve Gözle algoritması, ölçülen sistem parametrelerine bağlı olarak bir çıkış değeri üretmektedir. Yaygın olarak kullanılan bu algoritmanın davranışı Şekil 2'deki PV Güç-Gerilim grafiğinde verilmiştir. Şekilden görüldüğ̈̈ üzere, grafik üç temel bölüme ayrılabilir. Eşt. 1'deki türevsel ifadenin sıfirdan büyük olduğu durumda, güç artarken panel gerilimi de artmaktadır. Bu bölgede Maksimum Güç Noktasına (MPP) ulaşmak için dönüştürücüden akan gücün artırılması gerekmektedir. 


$$
\begin{cases}\frac{d P}{d V}>0 & P<M P P \\ \frac{d P}{d V}=0 & P=M P P \\ \frac{d P}{d V}<0 & P<M P P\end{cases}
$$

Güç artış1 doğrultusunda, türevsel ifadenin sıfıra eşit olduğu yani eğri üzerindeki değişimin sıfır olduğu nokta MPP olarak tanımlanmıştır. Tepe noktada güç değişimi olmadığından, eğri güç eksenine göre düz duruma gelmektedir. Bu nedenle türevsel ifade sıfıra eşitlenmektedir.

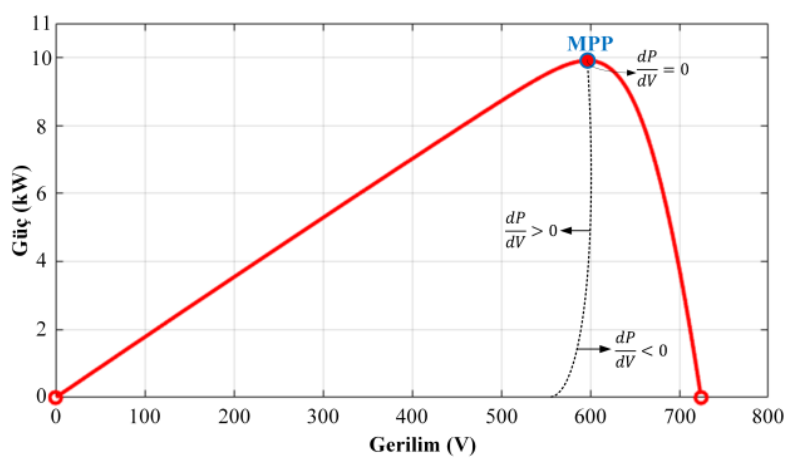

Şekil 2. Maksimum güç eğrisi

Maksimum güç noktasının sağ tarafında kalan bölümde ise güç değerinde azalma meydana geldiğinden, güç-gerilim türevi negatif değerler almaktadır. Bu bölümde gerilim artarken güç azalmaktadır. MPP noktasına ulaşmak için güç değerinin azaltılması gerekmektedir. Bununla birlikte gerilim değerinde de bir miktar azalma olarak sistem tekrar MPP noktasına ulaşacaktır.

Çalışma yapısı açıklanan MPPT algoritmasının tüm durumlarını içeren akış diyagramı Şekil 3 'te verilmiştir. Algoritma güneş paneli grubunun çıkışındaki anlık parametrelerin ölçümüyle başlamakta ve güç değerini hesaplamaktadır. Aynı zamanda, önceki güç değeri $\left(P_{(k-1)}\right)$ ve gerilim değerini $\left(V_{(k-1)}\right)$ güncel değerler ile karşılaştırarak değişim yönlerini tayin etmektedir. Eğer önceki güç değeri ile hesaplanan güç değeri aynı ise, bu durumda MPP tespit edilmiş olduğundan, referans akım değeri eski değere eşitlenmektedir. Güç değişimi var ise, yukarıda belirtilen açıklamalar doğrultusunda referans akım değerinin artırılması ya da azaltılması durumlarına karar verilmektedir. Bu algoritma sonucunda, üretilen referans akım değeri $\left(i_{\text {refpv }}\right)$ MPC algoritmasında kullanılarak maksimum güç kontrolü sağlanmaktadır[9]. 


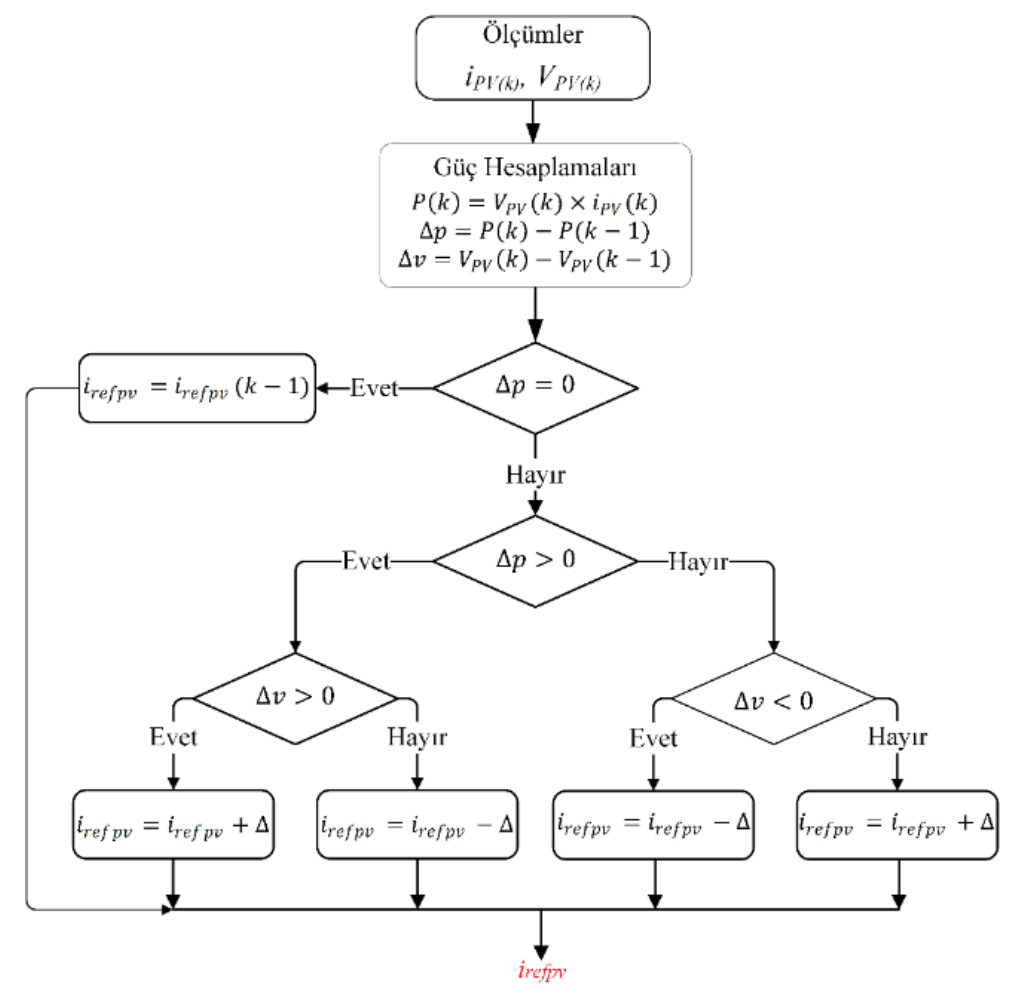

Şekil 3. MPPT algoritmasına ait akış diyagramı

\section{B. MODEL ÖNGÖRÜLÜ AKIM KONTROL ALGORITTMASI}

Model öngörülü kontrol algoritması, sistemlerin çalışma durumlarına göre hesaplanan maliyet fonksiyonları arasından en uygununu seçme prensibine dayalı olarak çalışan hızlı ve yüksek doğruluğa sahip bir kontrol metodudur. MPC algoritmasının güç dönüştürücülerine uygulanması üç adımda gerçekleşmektedir. Öncelikle kontrol parametresine ait matematiksel fonksiyon elde edilir. Sonrasında, tahmin fonksiyonu oluşturulur ve bu fonksiyon kullanılarak maliyet fonksiyonları elde edilir. Sistemin tüm çalışma durumları için elde edilen maliyet fonksiyonları minimize edilerek güç dönüştürücüsü için en uygun anahtar pozisyonları belirlenir.

\section{B. 1. Evirici Analizi}

Üç fazlı evirici ve LC filtreye ait devre şeması Şekil 4'te verilmiştir. Klasik yöntemlerde, evirici anahtarlar durumları sinüzoidal darbe genişlik modülasyonu gibi yöntemler ile belirlenirken, dijital kontrol metotları lojik sinyaller üreterek kontrol işlemlerini gerçekleştirmektedir. Uygulanan anahtarlama sinyallerine bağlı olarak elde edilen gerilimlerin sinüzoidal biçme getirilmesi için filtreler kullanılmaktadır. LC ve LCL tipi filtreler yaygın olarak kullanılmakla birlikte, LCL tip filtreler şebeke endüktansındaki değişimlerin sistem üzerindeki etkisini azaltmak için tercih edilmektedir. Şekil 4'te verilen evirici yapısında ise, evirici şebeke durumuna bağlı olarak ada durumda çalışmaya da geçmektedir. Bu nedenle LC tipi filtre tercih edilmiştir. Filtrede kullanılan endüktans ve kapasitans değerleri sırasıyla Eşt. 1 ve Eşt. 2 kullanılarak hesaplanmıştır. Bobin evirici çıkışına seri olarak bağlandığından dolayı gerilim düşümüne neden olmaktadır. Dolayısıyla, verim ve evirici girişine uygulanacak doğru gerilim genliği açısından oldukça etkilidir. Bu nedenle, güç ve frekans değerleri kullanılarak hesaplanan değerin \%10'u değerinde bir filtre endüktansı kullanımı önerilmektedir[5], [17], [18]. Benzer olarak, kondansatör kapasitesi belirlenirken reaktif güç tüketimi göz önünde bulundurulmaktadır. Yüksek değerli kapasite seçimi reaktif güç değerinde artışa neden olacağından, aktif gücün \%5'i kadar bir reaktif güç seçimi ile filtre kapasitansı belirlenmektedir[17]-[19]. 
$L_{f}=\frac{0.1 V_{i n v}^{2}}{2 \pi f P_{P V(\max )}}$

$C_{f}=\frac{0.05 P P V(\max )}{2 \pi f V_{i n v}^{2}}$

Tablo 2'de yer alan sistem parametreleri kullanılarak, filtre endüktansı 4.6mH ve filtre kapasitansı $10 \mu \mathrm{F}$ olarak hesaplanmıştır.

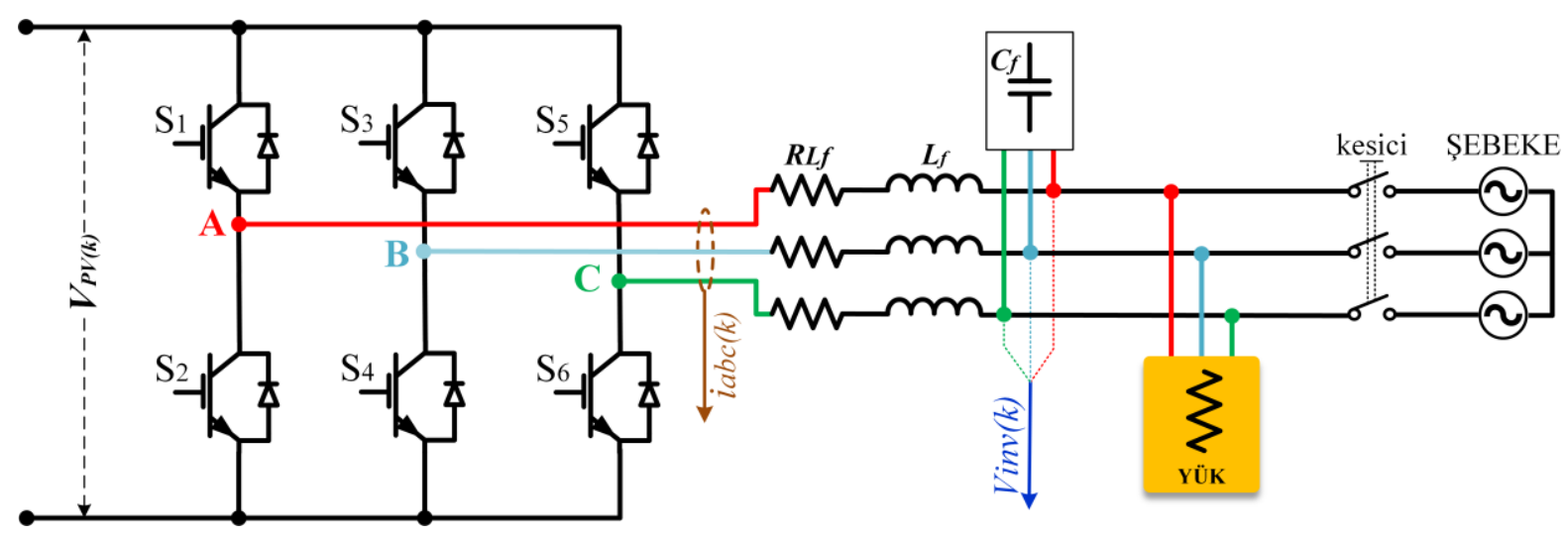

Şekil 4. Evirici devre şemast

Güç dönüştürücülerinin çalışma yapısı doğrudan anahtar konumlarına bağlılık gösterdiğinden, analizler de anahtar durumlarına göre gerçekleştirilmektedir. 3 fazlı ve iki seviyeli bir eviricinin Tablo 1 'de verilen 8 adet olası anahtar durumu bulunmaktadır [20]. Tablodan görüldüğü üzere, çıkış geriliminin genliği anahtar durumlarına göre değişkenlik göstermektedir.

Tablo 1. Anahtar durumlarına göre çıkış geriliminin vektörel ifadeleri

\begin{tabular}{ccccc}
\multicolumn{5}{c}{ Anahtar Durumları } \\
\hline $\mathbf{V}_{\mathbf{1}}$ & $\mathbf{S}_{\mathbf{1}}$ & $\mathbf{S}_{\mathbf{3}}$ & $\mathbf{S}_{\mathbf{5}}$ & Çıkış Gerilimi \\
$\mathbf{V}_{\mathbf{2}}$ & 1 & 0 & 0 & 0 \\
$\mathbf{V}_{\mathbf{3}}$ & 1 & 1 & 1 & 0 \\
$\mathbf{V}_{\mathbf{4}}$ & 1 & 1 & 0 & $\frac{1}{3} V_{P V}+j \frac{\sqrt{3}}{3} V_{P V}$ \\
$\mathbf{V}_{\mathbf{5}}$ & 0 & 1 & 0 & $-\frac{1}{3} V_{P V}+j \frac{\sqrt{3}}{3} V_{P V}$ \\
$\mathbf{V}_{\mathbf{6}}$ & 0 & 1 & 1 & $-\frac{2}{3} V_{P V}$ \\
$\mathbf{V}_{\mathbf{7}}$ & 0 & 0 & 1 & $-\frac{1}{3} V_{P V}-j \frac{\sqrt{3}}{3} V_{P V}$ \\
$\mathbf{V}_{\mathbf{8}}$ & 1 & 0 & 1 & $\frac{1}{3} V_{P V}-j \frac{\sqrt{3}}{3} V_{P V}$ \\
\hline
\end{tabular}

Anahtar durumları Clark dönüşümüne eklenerek evirici çıkış gerilimleri Eşt. 2'deki gibi ifade edilebilir [2]. 


$$
V_{(n)}=\frac{2}{3} V_{P V}\left[S_{1(n)}+\left(-\frac{1}{2}+j \frac{\sqrt{3}}{2}\right) S_{3(n)}+\left(-\frac{1}{2}-j \frac{\sqrt{3}}{2}\right) S_{5(n)}\right]
$$

Şekil 4’teki devre modeli üzerinden evirici gerilim eşitliği aşağıdaki gibi yazılabilir,

$$
V_{i n v}=V_{(n)}-V_{R L f}-V_{L f}
$$

Eşt. 3, bobin gerilimi için düzenlenecek olursa;

$$
L_{f} \frac{d i}{d t}=V_{(n)}-V_{i n v(k)}-V_{L f}
$$

Eşt. 4 düzenlenerek evirici çıkış akımı Eşt. 5'teki gibi ifade edilebilir.

$$
\frac{d i}{d t}=\frac{1}{L_{f}}\left(V_{(n)}-V_{i n v(k)}-i_{(k)} R_{L f}\right)
$$

\section{B. 2. Model Öngörülü Kontrol}

Model öngörülü kontrolün en önemli basamaklarından biri de tahmin fonksiyonudur. Klasik kontrol metotlarından farklı olarak MPC tekniğinde hata fonksiyonu, tahmin edilen değer ile referans değerin karşılaştırılmasıyla elde edilir. $\mathrm{Bu}$ nedenle kontrol değişkeni olan evirici akımının bir sonraki örnekleme süresindeki değerinin tahmin edilmesi gerekmektedir. Tahmin fonksiyonu ayrıklaştırma yaklaşımları ile oluşturulmaktadır. Eşt. 6'daki Forward-Euler metodu düşük mertebeli sistemlerin ayrıklaştırılmasında yaygın olarak kullanılan bir metottur. Eşt. 5'teki akım fonksiyonundaki türevsel ifade yerine ayrıklaştırma eşitliği yazılarak, akım tahmin fonksiyonu Eşt. 7'deki gibi elde edilir. Örnekleme zamanını da içeren bu fonksiyon sayesinde akımın bir sonraki örnekleme süresindeki değeri tahmin edilmektedir.

$$
\begin{aligned}
& \frac{d i}{d t} \approx \frac{i_{(k+1)}-i_{(k)}}{T_{s}} \\
& i_{(k+1)}=\frac{T_{s}}{L_{f}}\left(V_{(n)}-V_{i n v(k)}-i_{(k)} R_{L f}\right)+i_{(k)}
\end{aligned}
$$

MPC tekniğinde, tahmin fonksiyonundan sonra hatanın hesaplanması için maliyet fonksiyonları kullanılmaktadır. Birden çok kontrol parametresi aynı maliyet fonksiyonu içerisinde ifade edilebilmesi MPC tekniğinin bir avantajı olarak ön plana çıkmaktadır. Eşt. 8'de görüldüğü üzere, $\alpha-\beta$ koordinat düzleminde tahmin edilen akım değerleriyle referans akım değerleri $\left(i_{\alpha}^{*}\right.$ ve $\left.i_{\beta}^{*}\right)$ arasındaki mutlak hatalar hesaplanarak maliyet fonksiyonu oluşturulmuştur.

$$
g_{(k+1)}=\left|i_{\alpha}^{*}-i_{\alpha(k+1)}\right|+\left|i_{\beta}^{*}-i_{\beta(k+1)}\right|
$$

Oluşturulan model öngörülü akım kontrol algoritmasına ait akış diyagramı Şekil 5’te verilmiştir. Algoritma, referans akım değeri girişi ve ölçümler ile başlamaktadır. Sonrasında sabit sistem parametreleri tanımlanmaktadır. Eşt. 2'deki evirici gerilimi, Eşt. 7'deki tahmin ve Eşt. 8'deki maliyet fonksiyonu tüm anahtarlama durumları için hesaplanmaktadır. Sekiz anahtar durumu için elde edilen maliyet fonksiyonları arasından minimum değere sahip olan sonuca göre anahtar pozisyonları belirlenmektedir. $S_{2}, S_{4}$ ve $S_{6}$ anahtarlarının pozisyonları ise, sirasıyla $S_{1}, S_{3}$ ve $S_{5}$ 'in tersi olarak uygulanmaktadir. 


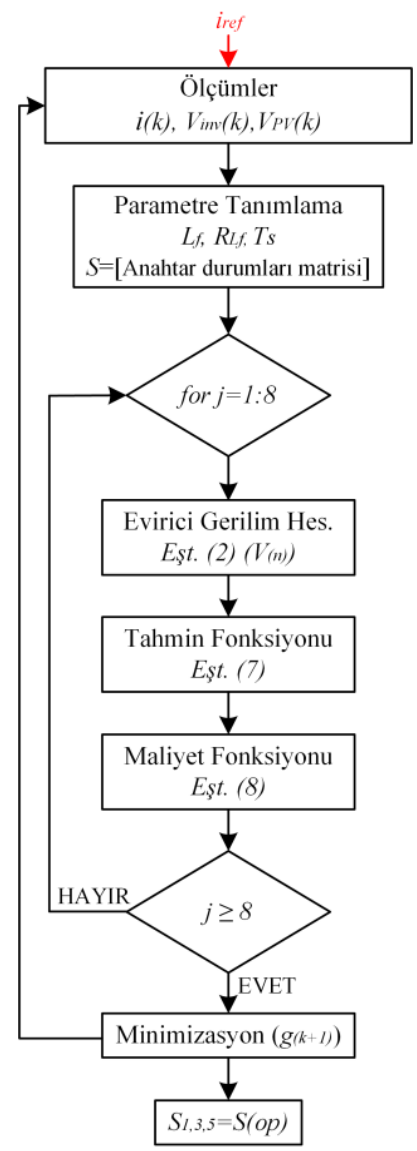

Şekil 5. Model öngörülü kontrol algoritmasinin akıs diyagramı

\section{B. GERILIIM KONTROLÜ}

Şebekede üretim olmadığı ve güneş panellerinde üretim olduğu durumda yüke güç akışının sürdürülmesi için gerilim kontrol yapısı kullanılmıştır. Sistem modelinde belirtildiği üzere, bu durumda evirici çıkış gerilimi ölçülerek sabit bir referans değer ile karşılaştırılmaktadır. Gerilim kontrollü çalışmada MPPT algoritması devre dışı kalmakta ve PI kontrolör çıkışı MPC algoritmasında referans olarak kullanılmaktadır. Bu nedenle, PI kontrolör gerilim hatasına bağlı olarak bir referans akım sinyali $\left(i_{\text {refada }}\right)$ üretmektedir. Şekil 6 'da verilen genel akıș diyagramından görüldüğü üzere, şebeke gerilimi $\left(V_{i n v}\right)$ standartlarda belirtilen limitler arasında değil ise, sistem ada duruma geçmekte ve gerilim kontrol algoritması etkin duruma gelmektedir. Aksi durumda ise, MPPT algoritması etkin durumdadır. 


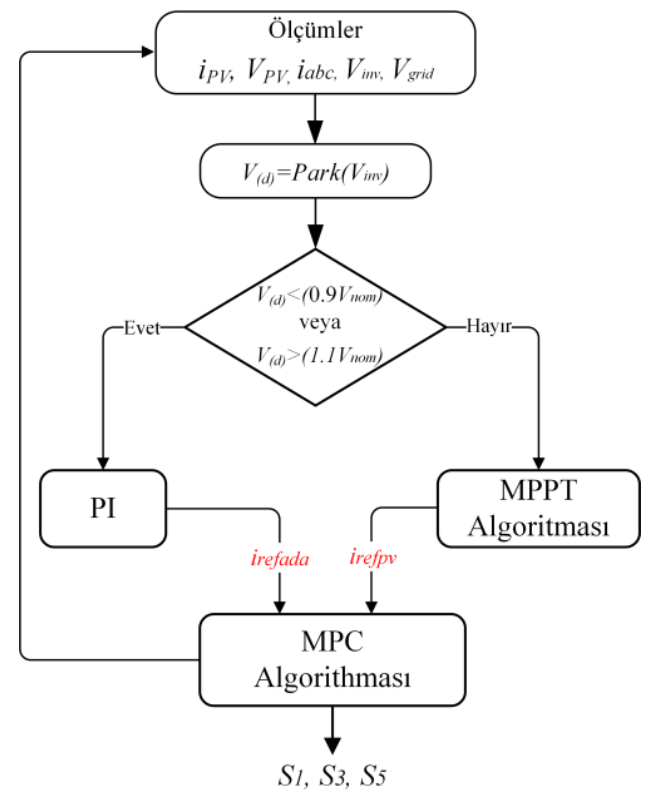

Şekil 6. Kontrol yapısının genel akış diyagramı

\section{BENZETIM SONUCLARI}

Önerilen sistemin doğrulanması için MATLAB/Simulink ortamında modelleme ve benzetim çalışmaları gerçekleştirilmiştir. Benzetim çalışmasında kullanılan parametreler Tablo 2'de verilmiştir. Güç ve kontrol yapılarının davranışlarının analiz edilmesi için bir senaryo oluşturulmuş ve olası tüm çalışma durumları incelenmiştir. Elde edilen benzetim sonuçları Şekil 7'de verilmiştir. Farklı çalışma koşullarını açıklamak için sonuçlar bölümlere ayrılmıştır. Grafiksel sonuçlarda akım ve gerilimler için etkin değerler verilmiştir.

Tablo 2. Benzetim parametreleri

\begin{tabular}{lc}
\hline \multicolumn{1}{c}{ Parametre } & Değeri \\
\hline Şebeke gerilimi & $380 \mathrm{~V}$ \\
Güneş paneli & $220 \mathrm{~W}, 39.8 \mathrm{~V}$ \\
Seri - Paralel panel sayısı & $15 \times 3$ \\
Örnekleme Süresi & $10 \mu \mathrm{s}$ \\
Filtre endüktansı $\left(\boldsymbol{L}_{f}\right)$ & $4.6 \mathrm{mH}$ \\
Filtre kapasitansı $\left(\boldsymbol{C}_{f}\right)$ & $10 \mu \mathrm{F}$ \\
\hline
\end{tabular}

\section{A süreci:}

Başlangıç anından şebeke gerilimi kesilinceye kadar devam eden bu süreçte yük geriliminin $\left(V_{Y U ̈ K}\right)$ şebeke gerilimine $\left(V_{S}\right)$ eşit olduğu Şekil 7(a) ve Şekil 7(b)'de görülmektedir. Aynı süreçte PV sistem gücünde artış olduğu, 1şınıma bağlı olarak çizdirilen Şekil 7(c)'deki $P_{M P P}$ grafiğinde görülmektedir. Bununla birlikte PV panellerden çekilen gücün de bu ideal güç grafiğine $\left(P_{M P P}\right)$ oldukça yakın seviyede olduğu grafiğin bu bölümü için söylenebilir. Bu sonuçlar aynı zamanda MPPT algoritmasının başarılı bir şekilde takip işlemini gerçekleştirdiğini de göstermektedir. Güneş panellerinde üretilen gücün artmasıyla, şebekeden çekilen $\operatorname{akımın}\left(i_{S}\right)$ azaldığı Şekil $7(d)$ 'deki akım grafiklerinden görülmektedir. Eviriciden sağlanan akımın, yüke aktarılandan $\left(i_{Y U ̈ K}\right)$ fazla olduğu durumda ise şebeke akımının negatif bölgeye geçtiği yine aynı grafikte görülmektedir. Bu durum, sistemden şebekeye doğru bir güç akışı olduğunun göstergesidir. Yine aynı grafikte, 4kW'lık bir yükün eklendiği durumda 
yük akımı artmış, bu durumda ise yüke aktarılan gücün bir kısmı şebekeden alınırken bir kısmı evirici üzerinden sağlanmıştır. Şekil 7(e)'deki sonuçlarda ise, MPC algoritmasına uygulanan referans akım sinyali ve evirici akımı görülmektedir. MPC algoritmasının referans değeri başarılı bir şekilde takip ettiği grafikten açıkça görülmektedir. Şekil 7(f)'deki şebekeye ait aktif $\left(P_{S}\right)$ ve reaktif $\left(Q_{S}\right)$ güç grafikleri, Şekil 7(d)'deki akım grafiğine benzer şekilde güç akışı olduğunu göstermektedir. Güç değerinin pozitif olması şebekeden yüke doğru bir güç akışı olduğunu, negatif taraflı olması ise sistemden şebekeye doğru güç akışının sağlandığını ifade etmektedir. Çalışma süresi boyunca kontrol algoritması sayesinde ortalama reaktif güç sıfır değerinde tutulmuştur.

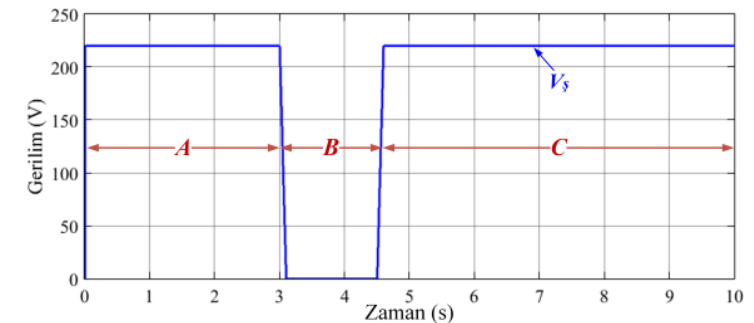

(a)

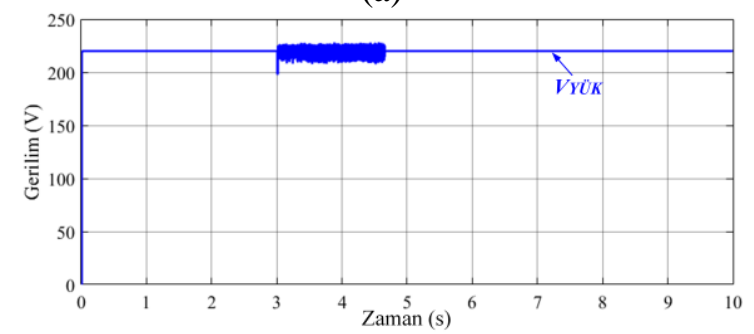

(b)

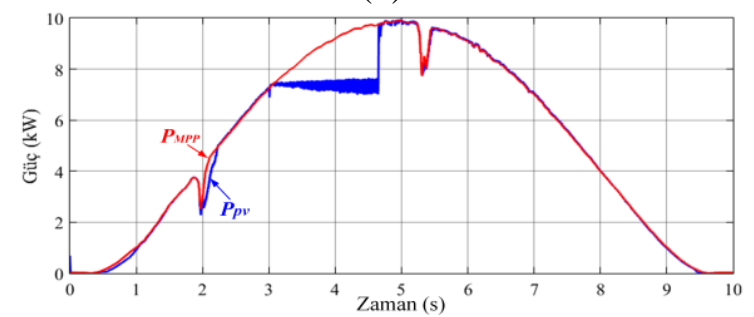

(c)

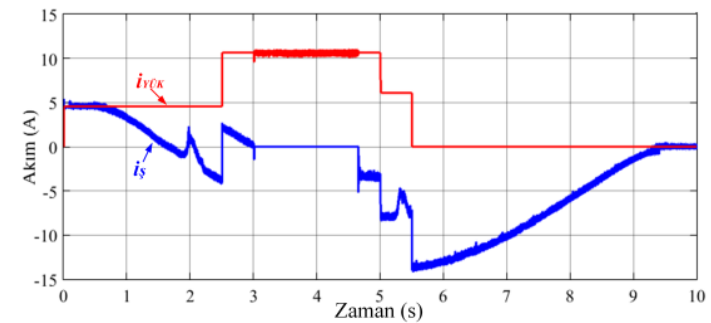

(d)

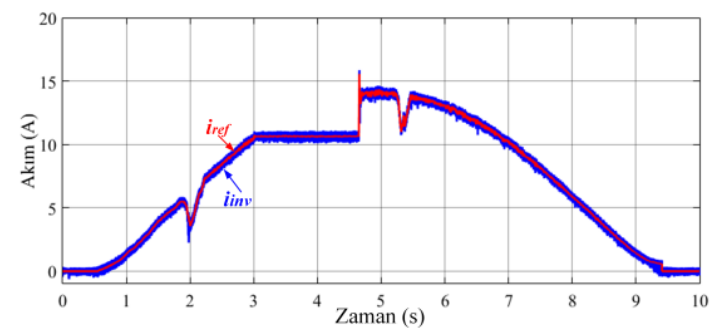

(e)

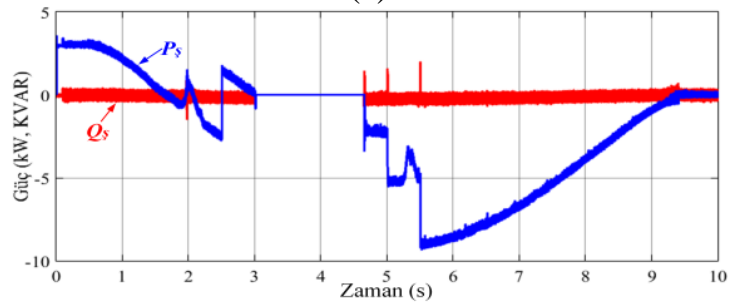

(f)

Şekil 7. Benzetim sonuçları, (a) Şebeke gerilimi (b) Yük gerilimi (c) Maksimum güç eğrisi ve PV gücü (d) Şebeke ve yük akımları (e) Evirici akımı ve referansı (f) Sebeke aktif ve reaktif gücü

B süreci: Bu sürecin başlangıcında şebeke gerilimi azalmış ve sistem ada duruma geçiş yapmıştır. Geçiş anının daha detaylı incelenmesi için şebeke ve yük gerilimleri Şekil 8'de verilmiştir. Şekilden görüldüğü üzere, 3s'den sonra şebeke gerilimi azalmaktadır. Bununla birlikte Şebeke Algılama algoritması gerilim değeri tolerans limitinin altına düştügünde, şebeke kesicisini 3.01'inci saniyede açmış ve ada duruma geçişi sağlamıştır. Şekil 8(b)'deki sonuçlardan görüldüğü üzere, geçiş anından itibaren yük gerilimi eski değerine ulaşmıştır. Bu durumda yük yalnız PV panellerden beslenmekte ve sistem gerilim kontrollü olarak çalışmaktadır. Ada durumda yüke uygulanan gerilim kalitesinin incelenmesi için toplam bozulma sonucu Şekil 9' da verilmiştir. Şekilden görüldügü üzere, toplam bozulma standartlarda[21] belirtilen $\% 8$ limitinin oldukça altında ve \%1,65 seviyesindedir. Şekil 7'deki sonuçlardan görüldüğü üzere, B sürecinde şebekeden herhangi bir güç akışı olmaz iken, gerilim tabanlı çalışmadan dolayı MPPT algoritması devre dışı kalmıştır. Bu nedenle PV'de üretilen gücün bir kısmı kullanılamamaktadır. 


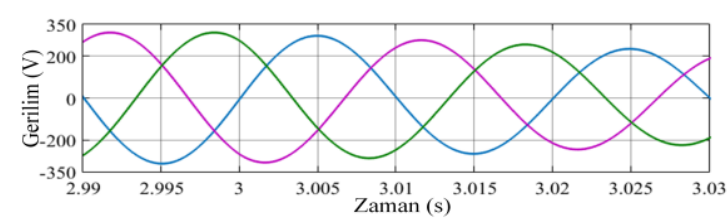

(a)

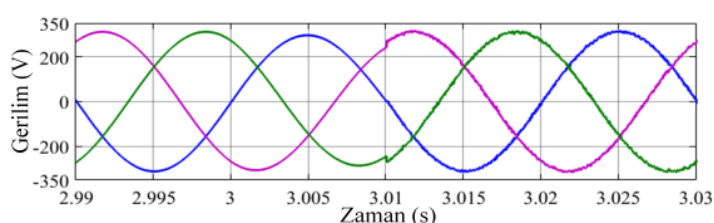

(b)

Şekil 8. Ada duruma geçiş sonuçları, (a) Şebeke gerilimi (b) Yük gerilimi

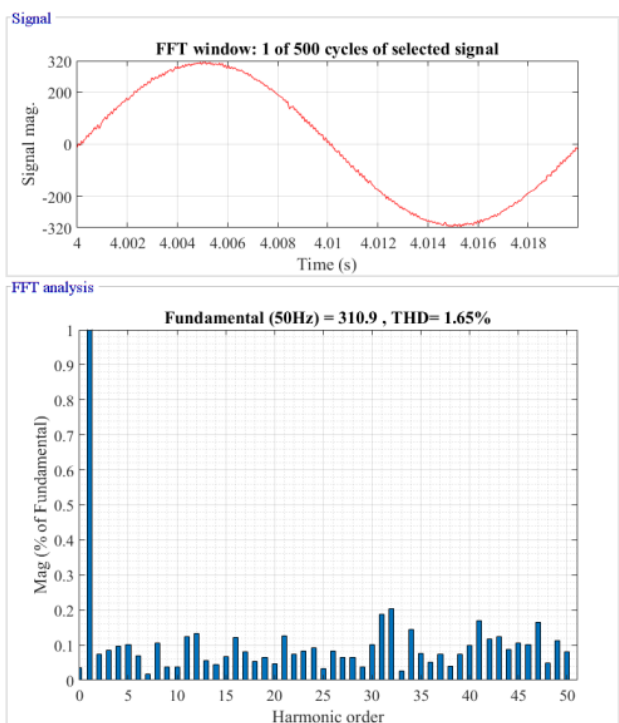

Şekil 9. Ada duruma gerilime ait toplam bozulma sonucu

\section{C süreci:}

Şebeke geriliminin artmasıla Şebeke Algılama algoritması kesiciyi kapatılmış ve MPPT algoritmasının çıkış sinyali MPC algoritmasında referans olarak kullanılmaya başlanmıştır. Bu durum Şekil 7(c)'deki PV güç grafiğinde açıkça görülmektedir. Süreç başlangıcında PV'de üretilen güç, yükte tüketilenden fazla olduğundan dolayı $\operatorname{artan} 2 \mathrm{~kW}$ 'lık güç şebekeye gönderilmektedir. Sonrasında yük akımının azalmasıyla şebekeye gönderilen güç $5 \mathrm{~kW}$ seviyesine yükselmiștir. Kontrol algoritmalarının takip kabiliyetini test etmek için benzetim süresi boyunca iki adet gölgelenme etkisi oluşturulmuştur. C sürecinde meydana gelen gölgelenme etkisini detaylı olarak incelemek için Şekil 10 'daki sonuçlar verilmiştir. Gölgelenme sonucu olarak PV'de üretilen güç $9.8 \mathrm{~kW}$ seviyesinden 7.7kW'a azalmıştır. Bununla birlikte referans akım değerinin de azaldığ görülmektedir. İlerleyen süreçte ş̧ınımın artmasıyla ideal PV gücü $\left(P_{M P P}\right)$ ve PV panellerden çekilen gücün $\left(P_{P V}\right)$ artığ1 Şekil 10(a)'da görülmektedir. Referans akımın ideal güç eğrisi ile benzerlik göstermesi MPPT algoritmasının takip işlemini gerçekleştirdiğini göstermektedir. Aynı zamanda model öngörülü akım kontrol algoritmasının referans akımdaki küçük değişimlerde bile hassas bir davranış sergilediği Şekil 10(b)'deki sonuçlarda görülmektedir.

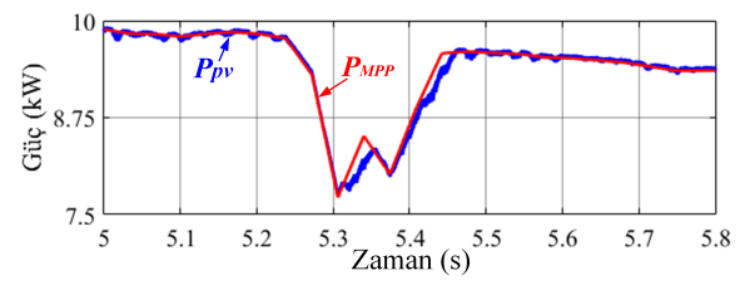

(a)

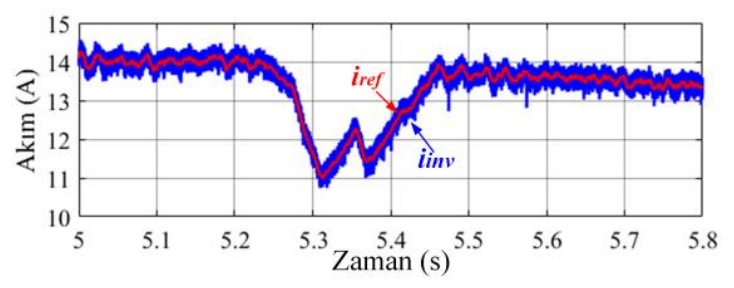

(b)

Şekil 10. Gölgelenme etkisi sonuçları (a) Güç sonuçları (b) Akım sonuçları

C sürecinin son bölümünde (5.5s sonrası), dâhili yüklerin devre dışı kaldığı durum incelenmiștir. Bu süreçte evirici çıkış akımının doğrudan şebekeye aktarıldığı, Şekil 7(d) ve Şekil 7(e)'deki sonuçlarda 
görülmektedir. Benzetim sürecinin sonuna kadar devam eden bu durumda PV'de üretilen güce bağl1 olarak şebekeye aktarılan güç değişim göstermiştir. Şebeke bağlı durumda bozulmaların incelenmesi için toplam akım bozulması sonuçları Şekil 11'de verilmiştir. Ada durumda olduğu gibi, şebeke bağlantılı durumda da toplam bozulma sonuçları standartlarda[21] belirtilen \%5 sınırının altında ve $\% 2.15$ 'tir.

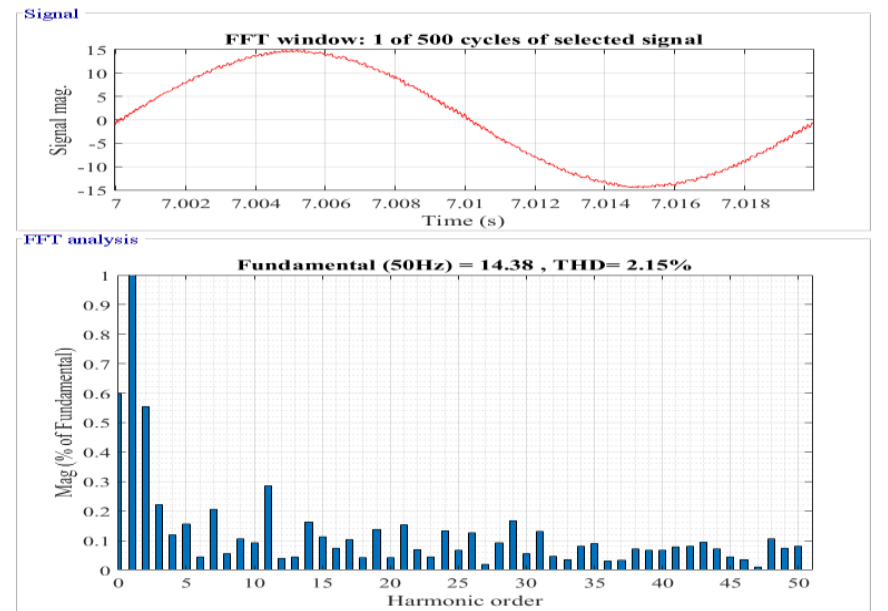

Şekil 11. Şebeke bağlantılı durumda akımdaki toplam bozulma sonucu

Benzetim çalışması boyunca elde edilen verim grafiği Şekil 12'de verilmiştir. İdeal PV gücü ile evirici çıkış gücü kullanılarak hesaplanan sistem veriminin, $1 \mathrm{~kW}$ üzeri güç değeri için $\% 94$ ve üzerinde olduğu şekilde görülmektedir. İdeal PV gücü kullanılarak hesaplanan verim sonuçları aynı zamanda maksimum güç takibi verimini de barındırmaktadır.

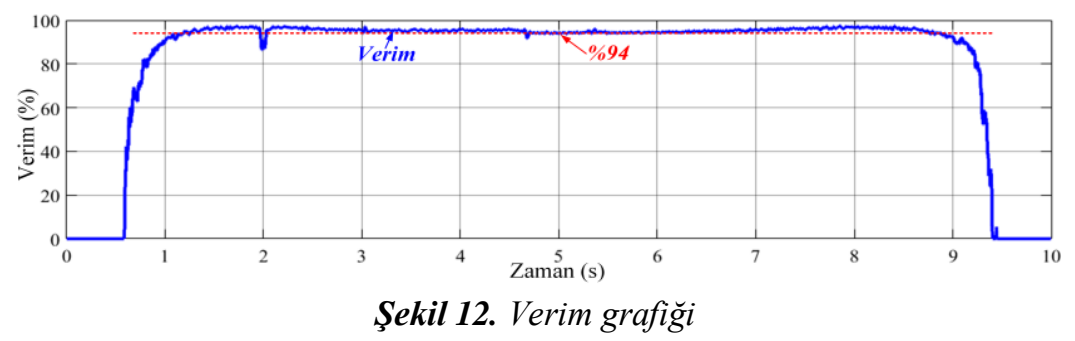

Önerilen sistem, tüm çalışma koşullarını içeren benzetim çalışmasıyla doğrulanmıştır. Elde edilen sonuçlar, şebeke bağlantılı durumdan ada duruma geçildiğinde, sistemin gerilim kontrollü olarak çalışmasını sürdürdüğü göstermiştir. MPC algoritmasının hassas ve hızlı bir kontrol yeteneğine sahip olması geçiş süreçlerinde meydana gelebilecek gerilim sıçramaları gibi olumsuzlukların engellenmesinde önemli rol oynamaktadır. Bununla birlikte MPPT algoritmasıyla uyumlu bir çalışma sürdürerek PV panellerde üretilen gücün maksimum seviyede kullanılmasını sağladığı da yine sonuçlarda görülmüştür.

\section{SONUC}

Önerilen bu çalışma ile şebeke bağlantılı ve ada durumda çalışabilen bir PV sistem tasarımı ve kontrolü gerçekleştirilmiştir. Bu amaçla, şebeke durumu algılanarak sistemin çalışma yapısı belirlenmiştir. Şebeke bağlantılı durumda PV panellerde üretilen gücün maksimum seviyede kullanılması için MPPT algoritması kullanılmıştır. Bu algoritma MPC metodu ile birleştirilerek hassas ve hızlı bir kontrol kabiliyeti elde edilmiştir. Hem şebeke bağlantılı hem de ada durumda evirici kontrolünü gerçekleştiren MPC metodunun geçiş durumlarında oldukça iyi bir performans sergilediği yapılan benzetim çalışmalarında görülmüştür. Ayrıca, şebeke bağlantılı ve ada durumlar arasındaki geçişlerde de kontrol yapısının oldukça iyi bir geçiş sağladığı yine benzetim çalışmalarının bir sonucu 
olarak belirtilebilir. Sistem ada durumdayken elde edilen genlik ve bozunum sonuçları yüklere uygulanan gerilimin \%1.65 gibi düşük bir bozulmaya sahip olduğunu göstermiş̧ir. Şebeke bağlantılı durumda ise akım üzerindeki toplam bozulma \%2.15 seviyesinde olmuştur. Her iki durumda da standartlarda belirtilen toplam bozulma sınırlarının oldukça altında değerler elde edilmiştir. Bununla birlikte sistem veriminin \%94 ve üzeri seviyelerde olduğu yapılan benzetim çalışması sonucunda görülmüştür.

\section{KAYNAKLAR}

[1] F. Evran, "Grid Connected Inverter,” Düzce Univ. J. Sci. Technol., vol. 6, pp. 1420-1429, 2018.

[2] N. Güler and E. Irmak, "MPPT Based Model Predictive Control of Grid Connected Inverter for PV Systems," in 2019 8th International Conference on Renewable Energy Research and Applications (ICRERA), pp. 982-986, 2019.

[3] E. Kabalci, Y. Kabalci, R. Canbaz, and G. Gokkus, "Single phase multilevel string inverter for solar applications," 2015 Int. Conf. Renew. Energy Res. Appl. ICRERA 2015, pp. 109-114, 2015.

[4] Y. Kabalci, E. Kabalci, R. Canbaz, and A. Calpbinici, "Design and implementation of a solar plant and irrigation system with remote monitoring and remote control infrastructures," Sol. Energy, vol. 139, pp. 506-517, 2016.

[5] Ş. Özdemir, Doktora Tezi, "Yenilenebilir Enerji Kaynakları İçin Tek Aşamalı Mppt Denetimli Çok Seviyeli Eviricinin Gerçekleştirilmesi," Gazi Üniversitesi Gazi Üniversitesi Fen Bilimleri Enstitüsü, 2013.

[6] D. Haji and N. Genc, "Fuzzy and PO Based MPPT Controllers under Different Conditions," 7th Int. IEEE Conf. Renew. Energy Res. Appl. ICRERA 2018, vol. 5, pp. 649-655, 2018.

[7] E. Kurak, V. Erdemir, ve B. Dursun, "PV Sistemin İçin Maksimum Güç Noktası İzleyicisi Tasarımı ve Uygulaması," Düzce Üniversitesi Bilim ve Teknol. Derg., c. 4, , ss. 293-304, 2016.

[8] E. Irmak and N. Güler, "Application of a high efficient voltage regulation system with MPPT algorithm," Int. J. Electr. Power Energy Syst., vol. 44, no. 1, pp. 703-712, 2013.

[9] E. Irmak and N. Güler, "A model predictive control-based hybrid MPPT method for boost converters," Int. J. Electron., vol. 107, no. 1, pp. 1-16, 2020.

[10] N. Ozturk, R. Canbaz, and E. Celik, "Constant voltage constant frequency control for single phase three level inverter," 2012 Int. Conf. Renew. Energy Res. Appl., pp. 1-5, 2012.

[11] H. Komurcugil and S. Biricik, "Time-Varying and Constant Switching Frequency-Based Sliding-Mode Control Methods for Transformerless DVR Employing Half-Bridge VSI," IEEE Trans. Ind. Electron., vol. 64, no. 4, pp. 2570-2579, 2017.

[12] N. Altin, S. Ozdemir, H. Komurcugil, and I. Sefa, "Sliding-Mode Control in Natural Frame with Reduced Number of Sensors for Three-Phase Grid-Tied LCL-Interfaced Inverters," IEEE Trans. Ind. Electron., vol. 66, no. 4, pp. 2903-2913, 2019.

[13] H. Komurcugil, S. Bayhan, F. Bagheri, O. Kukrer, and H. Abu-Rub, "Model-Based Current Control for Single-Phase Grid-Tied Quasi-Z-Source Inverters with Virtual Time Constant," IEEE Trans. Ind. Electron., vol. 65, no. 10, pp. 8277-8286, 2018. 
[14] H. Komurcugil and S. Bayhan, "Sliding Mode Control Strategy for Three-Phase Three-Level T-Type PWM Rectifiers with Capacitor Voltage Imbalance Compensation," IECON 2019 - 45th Annu. Conf. IEEE Ind. Electron. Soc., vol. 1, pp. 3571-3576, 2019.

[15] TEDAŞ, "Lisanssız Elektrik Üretim Yönetmeliği Kapsamında 10kW ve Altı Çatı ve Cephe Uygulamalı Güneş Elektrik Üretim Tesisleri için Tip Proje ve Ekleri,” 2018.

[16] C. Andrus, "Understanding IEEE 1159 Definitions", Power Monitors Inc., 2016.

[17] H. Markiewicz and A. Klajn, "Voltage Disturbances,", Standard EN 50160-Voltage Characteristics of Public Distribution Systems, Wroclaw Univ. of Tech., 2004.

[18] M. Ben Said-Romdhane, M. W. Naouar, I. S. Belkhodja, and E. Monmasson, "An improved LCL filter design in order to ensure stability without damping and despite large grid impedance variations," Energies, vol. 10, no. 3, 2017.

[19] N. Güler ve E. Irmak, "Nötr Kenetlemeli Eviriciler için Çok Giriş - Çok Çıkışlı DA-DA Çevirici Tasarımı ve Kontrolü," Gazi Üniversitesi Fen Bilim. Derg. Part C Tasarım ve Teknol., c. 7, s. 1, ss. 49-62, 2019.

[20] J. Rodriguez and P. Cortes, Predictive control of power converters and drives. Wiley, 2011.

[21] IEEE Recommended Practice and Requirements for Harmonic Control in Electric Power Systems," in IEEE Std 519-2014 (Revision of IEEE Std 519-1992), vol., no., pp.1-29, 11 June 2014. 